\title{
China's Rural Cooperative Medical Scheme: a type of health insurance or a type of health cooperative?
}

\author{
Fang Wang and Yuan Liang \\ Department of Social Medicine and Health Management, School of Public Health, Tongji Medical College, \\ Huazhong University of Science and Technology, Wuhan, China
}

\begin{abstract}
The Cooperative Medical Scheme (CMS) was popular in rural China in the 1960s and 1970s, having garnered praise from the World Bank and World Health Organization as an unprecedented example of a successful health care model in a low-income developing country. However, the CMS almost collapsed in the 1980s. Based on its historical origins and main activities, we think the CMS functioned as a health cooperative rather than a health insurance scheme. Perhaps, however, the importance to the CMS of cooperation between institutions has been overestimated. Overlooked, yet equally important, has been the cooperation between health workers and farmers to target health-related risk factors associated with agricultural work and ways of life. The 'cooperative' character of the CMS includes two aspects: cooperative institutions and cooperative behaviour. Although the CMS collapsed in China, similar schemes are flourishing elsewhere in the world. In the future, in-depth analysis of these schemes is required.
\end{abstract}

Key words: Cooperative Medical Scheme; health cooperative; health insurance; health reform; primary health care

Received 20 September 2015; revised 24 March 2016; accepted 25 April 2016; first published online 19 May 2016

\section{A perplexing problem about China's Rural Cooperative Medical Scheme (CMS)}

China's CMS, popular in the 1960s and 1970s for its widespread benefits to farmers in rural China, was highly praised by the World Bank and World Health Organization (WHO). The scheme was considered an unprecedented example of a successful health care model in a low-income, developing country. However, the CMS almost collapsed in the 1980s (Zhu et al., 1989; Chen et al., 1993; White, 1998). Although the central government of China has worked actively to reconstruct the CMS, renaming it the New Cooperative Medical Scheme (NCMS), the NCMS has achieved only some of its goals, and provided farmers limited financial protection

Correspondence to: Yuan Liang, PhD, Department of Social Medicine and Health Management, School of Public Health, Tongji Medical College, Huazhong University of Science and Technology, Hangkong Road 13, Wuhan 430030, Hubei Province, China. Email: liangyuan217@163.com
(Green, 2004; Yip and Hsiao, 2009; Zhang et al., 2010; Liu et al., 2011; Liang et al., 2012; Yang, 2013).

To date, the vast majority of research on the NCMS has considered it as a type of health insurance for farmers (Anson and Sun, 2004; Liang et al., 2012). However, two questions arise if the CMS was really just an insurance system. First, why was the CMS so successful in the poor and underdeveloped China of the pre-economic reform era? Second, why was it so difficult to reconstruct a similar insurance system model in the rich and rapidly developing China of the 21st century? In fact, based on the historical origin and main activities of the CMS (China's Rural Cooperative Medical Scheme Act (draft), 1979; Liu, 2008), it likely functioned as a health cooperative rather than a health insurance system.

\section{The CMS as a type of health cooperative}

The CMS was internationally famous in the 1970 s as a community-based cooperative health system.

(C) Cambridge University Press 2016 
At the 1978 Alma Ata conference, China's experience of the CMS was praised as an holistic primary health care system, not just a health insurance system (Sidel, 1972a, 1972b; Sidel and Sidel, 1982). However, during the 1980s and 1990s, the international literature came to regard the CMS as a type of health insurance (Zhu et al., 1989; Shi, 1993; Feng et al., 1995), and almost all international papers written in the last two decades have regarded the CMS as a rural insurance system.

To the best of our knowledge, most international scholars are only familiar with the CMS in the new China, namely the post-liberation period after 1949. However, the CMS already existed in pre-liberation rural China. According to Liu (2008), a scholar of the rural social history of modern China, the origin of the CMS can be traced back to rural cooperative movements in northern China in the 1920s. Especially important was the China Huayang Disaster Relief Cooperative (1923-1929), which was followed by the China Commonalty Education Promotion Association of Dingxian County, Hubei (1929-1937). Later came a pilot scheme of the CMS implemented in certain regions, including Xiaoyuanli Village, Huibei District, Wuxi, Jiangsu (1936-1937), and this scheme was followed by the health cooperative in Shan-gan-ning District, northwest China (1938-1946). In Liu's view, the core of the CMS was 'health care provided through cooperation'. As an example, the China Huayang Disaster Relief Cooperative was a charitable organization self-organized by local farmers with a branch named the Department of Drugs. The cooperative regularly organized its members to check community and family health, sweep streets and collect litter, and provided smallpox vaccinations in the spring. The Department of Drugs was funded from the public accumulation fund of the China Huayang Disaster Relief Cooperative. The cooperative stipulated that 'both members and non-members as well as villagers, including neighbouring villagers, will have their every request granted and shall not be charged', indicating that the emphasis was on providing free health care. According to Liu, the CMS collapsed due to the invasion of China by Japan (1931-1945). In addition, as in the pre-liberation period, Mao Zedong, the first Chairman of the New China, pointed out that 'Cooperativization is the only way for to realize the liberation of the poor and the only way for the poor to become rich' (Yan, 2007; Wang, 2008). Although this statement was intended to be a general reference to social issues, it was also considered an embodiment (or deduced result) of Mao Zedong's thoughts on health. Many researchers interested in China agreed with the conclusion: 'If there were no cooperative movements in rural areas, there would be no CMS in China' (Horn, 1972; Yan, 2007; Wang, 2008). In contrast, no researchers agreed with the alternative statement: 'if there was no insurance in rural areas, there would be no CMS in China'. Both before and after the founding of the new China, the CMS was considered to be derived not from an insurance system, but rather from a cooperative system.

Conversely, to our knowledge, China's Rural Cooperative Medical Scheme Act (draft), promulgated by the Ministry of Health of the People's Republic of China on 15 December 1979, was the earliest government declaration on the CMS (China's Rural Cooperative Medical Scheme Act (draft), 1979). The Act can be considered the most authoritative source for the missions/main activities of the CMS, and its content is as shown in Box 1.

According to the Acts, the CMS was mainly organized at the level of administrative villages, each of which generally included about 10 natural villages. At that time in China, and even now, the population of an administrative village was generally about 2000 people, and rarely exceeded 5000 people. Obviously, there are barriers to effectiveness for a health insurance system with participation of only about 2000 members. However, the CMS was very effective and was praised by the World Bank and WHO. In addition, it is worth noting the role of the 'barefoot doctors' in the CMS. The name 'barefoot doctors' was a vivid and formal description of their work pattern, specifically that they would remove their shoes and socks (i.e., go barefoot) and go into the paddy fields to work and live together with farmers (Sidel, 1972a, 1972b; White, 1998). This work pattern could involve cooperation between health workers and farmers or among those in need of health care, agricultural work and participating in the farmers' way of life, and such cooperation could also include innovative behaviour. Barefoot doctors could use their unique work pattern to directly and closely observe, analyse, and treat 


\section{Box 1 The missions/main activities of the CMS}

(1) Promote and implement national health policies.

(2) Launch a nationwide patriotic health campaign focussed on pest and disease control; provide technical guidance for 'manage two and improve five' (i.e., manage water, manage sewage, improve wells, improve latrines, improve pens for livestock, improve stoves, and improve the environment); strengthen vaccination programmes, infectious disease management, and reporting of epidemic outbreaks.

(3) Go to great lengths to improve the quality of medicine and serve the people with heart and soul.

(4) Strongly emphasize methods of collecting, cultivating, processing, and utilizing Chinese herbs to fully exploit herbal resources in disease prevention and treatment.

(5) Provide technical training and support the production brigade's hygienists and midwives.

(6) Advocate late marriage and family planning, and implement contraceptive measures.

(7) Provide women with knowledge regarding menstruation, labour, pregnancy, and the perinatal and breastfeeding periods; promote scientific pregnancy care and delivery; guarantee the smooth/normal operation of health care in kindergartens.

(8) Promote the popularization of scientific knowledge about health and dispel superstition; prevent accidents such as pesticide poisoning, food poisoning, electric shock, and trauma; provide training in wartime battlefield rescue techniques, and develop training programmes regarding atomic warfare, chemical warfare, and bacteriological warfare.

Source: China's Rural Cooperative Medical Scheme Act (draft) (1979)

health-related risk factors in farmers' working and living context (Horn, 1972; Sidel, 1972a, 1972b; China's Rural Cooperative Medical Scheme Act (draft), 1979; White, 1998; Yan, 2007; Wang, 2008). In so doing, they had the opportunity to provide timely disease surveillance, early warning detection, and early intervention in addition to regular health care, all of which functions were unrelated to health insurance. In addition, although the importance of cooperative institutions for the CMS has always been stressed, but perhaps an equally important phenomenon of the CMS has been ignored. This phenomenon is cooperative behaviour involving health workers and farmers, or balancing the needs of health care, agricultural work, and farmers' way of life in targeting health-related risk factors. This is a phenomenon that existed in both the historical origin and main activities of the CMS. The 'cooperative' element of the CMS proposed here includes the two aspects of cooperative institutions and cooperative behaviour.
In theory, the CMS embodies a collaborative approach to health affairs, together with the advantages it entails. Standing alone, the medical care delivery section or disease control and prevention section cannot effectively address the burden of disease and illness in a population. Instead, to effectively address this, broader cross-sector collaboration is considered essential (Alexander et al., 2003; Nicola, 2005). The literature considers collaborative advantage, mostly focussing on the elements of collaboration, such as vision and mission, action planning, leadership, and resources for mobilization. However, the next essential question is how to create collaborative advantage (Fawcett et al., 2000; Dowling et al., 2004). In this regard, the CMS may provide an operational mechanism for creating a collaborative advantage that incorporates the following two aspects. The first aspect is a mechanism of internal elements, namely the parties involved in cooperation (cooperation between the health sector and the working and living sector), as well as the specific details of 
cooperation (direct and close observation, analysis, and treating health-related risk factors in farmers' working and living context). The second aspect is a mechanism of external elements, namely voluntary collaboration between internal elements combined with external policy support and advocacy. According to China's Rural Cooperative Medical Scheme Act (1979 draft), the CMS receives no financial support from central or local government.

\section{A preliminary analysis on the reconstruction of the CMS}

The CMS-related literature of the past 20 years has almost universally regarded the reconstruction of the CMS (namely the NCMS) as a health insurance system intended to serve rural areas, and the payment of premiums has been taken to represent farmers' enrolment in the NCMS (Anson and Sun, 2004; Wang et al., 2008; Zhang et al., 2010; Jiang et al., 2011; Liang et al., 2012; Yang, 2013). In the case of the NCMS, enormous misunderstanding or bias would result from a lack of awareness of the cooperative behaviour mentioned above. Such misunderstanding or bias can provide a useful clue for explaining the perplexing problem described above: namely how to account for the success of the CMS success in pre-economic reform China, and for its lack of success in 21st century China.

Although many studies have shown that the NCMS has a coverage rate superior to that of the CMS, as well as increased outpatient and inpatient utilization, the NCMS nevertheless provides limited financial protection and fails to relieve the economic burden from disease experienced by farmers (Zhang et al., 2010; Jiang et al., 2011; Yang, 2013). Some researchers reported that government investment in public health and primary care was considered unsustainable (Wang et al., 2011). In some poor areas, the government is the exclusive sponsor of the NCMS (which essentially resembles health insurance) ( $\mathrm{Xu}$ and Tan, 2002; Fu, 2011; Yang, 2011), meaning the NCMS becomes a government-run 'one-man show'. Perhaps such a situation is unsurprising given that China remains a developing country with the largest agricultural population in the world. However, the fundamental transformation of China's political and economic institutions means that a complete return to the CMS of the pre-economic reform era may be very difficult. Nevertheless, it is possible to promote cooperation between health workers and farmers or between health care provision and agricultural work, together with awareness of the farmers' way of life. Such cooperation would target health-related risk factors, or function as a holistic primary health care system as proposed at the 1978 Alma Ata conference. As a developing country, rural China needs health insurance, but perhaps needs the CMS even more.

There is a further problem related to the CMS that deserves attention. Although the CMS in China was a product of the last century, health co-operatives are neither an old measure (in fact they are newer than health insurance) nor an outdated, dilapidated approach (Nayar and Razum, 2003; Stewart et al., 2003; Scutchfield, 2009). According to the International Health Cooperative Organization, health co-operatives currently serve at least 100 million households worldwide, in various countries, including Canada, the United States, India, Japan, Benin, Mali, and Uganda, and efforts are underway to include health co-operatives in current health care reform in the United States. Health co-operatives have different forms, including worker-owned organizations, consumer-owned organizations, jointly owned organizations (with ownership shared among consumers, workers, and communities), and purchasing or shared service cooperatives (Nayar and Razum, 2003; McLean and Sutton, 2008; International Health Co-operative Organization 2013). Although the past 20 years have seen negative experiences related to the development of health co-operatives, there is renewed interest in their revival in both developing and developed countries (Grembowski et al., 2008; McLean and Sutton, 2008; Ralston et al., 2009). In other words, although the CMS collapsed in China, similar schemes are flourishing elsewhere in the world. In the future, in-depth analysis of these schemes is required, with a special focus in ethnographic research on the elements of collaboration and cooperative relationships, cooperative behaviour and health risk factors and health outcomes.

\section{Acknowledgements}

The authors thank National Natural Science Foundation of China for funding this study. The 
authors acknowledge the valuable comments of the anonymous PHCRD reviewer.

\section{Financial Support}

This study was supported by grants from National Natural Science Foundation of China (no. 71273098). The funders had no role in study design, data collection and analysis, decision to publish, or preparation of the manuscript.

\section{Conflicts of Interests}

The authors have declared that no conflicts of interest exist.

\section{References}

Alexander, J.A., Weiner, B.J., Metzger, M.E., Shortell, S.M., Bazzoli, G.J., Hasnain-Wynia, R., Sofaer, S. and Conrad, D.A. 2003: Sustainability of collaborative capacity in community health partnerships. Medical Care Research and Review 60 (4 Suppl), 130S-60S.

Anson, O. and Sun, S. 2004: Health inequalities in rural China: evidence from HeBei province. Health Place 10, 75-84.

Better Health \& Social Care. 2014: Vol. 1 Report. How are Co-ops \& mutuals boosting innovation \& access worldwide? International Health Co-operative Organization. Retrieved 10 May 2016 from https://previewihco.files.wordpress.com/ 2014/10/report_lps_vol1.pdf.

Chen, X.M., Hu, T.W. and Lin, Z. 1993: The rise and decline of the cooperative medical system in rural China. International Journal of Health Services 23, 731-42.

China's Rural Cooperative Medical Scheme Act (draft). 1979: Promulgated on December 15, 1979 by Ministry of Health of People's Republic of China (in Chinese).

Dowling, B., Powell, M. and Glendinning, C. 2004: Conceptualising successful partnerships. Health and Social Care in the Community 12, 309-17.

Fawcett, S.B., Francisco, V.T., Paine-Andrews, A. and Schultz, J.A. 2000: A model memorandum of collaboration: a proposal. Public Health Reports 115, 174-79.

Feng, X., Tang, S., Bloom, G., Segall, M. and Gu, Y. 1995: Cooperative medical scheme in contemporary rural China. Social Science \& Medicine 41, 1111-118.

Fu, D. 2011: Summarization of financing models of China's cooperative medical scheme. Modern Preventive Medicine (in Chinese) 38, 4892-893.

Green, A. 2004: Have health sector reforms strengthened PHC in developing countries? Primary Health Care Research and Development 5, 289-95.

Grembowski, D., Anderson, M.L., Conrad, D.A., Fishman, P.A., Larson, E.B., Martin, D.P., Ralston, J.D., Carrell, D. and Hecht, J. 2008: Evaluation of the group health cooperative

Primary Health Care Research \& Development 2017; 18: 194-199 access initiative: study design challenges in estimating the impact of a large-scale organizational transformation. Quality Management in Health Care 17, 292-303.

Horn, J.S. 1972: Building a rural health service in the People's Republic of China. International Journal of Health Services 2, 377-83.

Jiang, Q., Jiang, Z., Zhao, M., Tao, J., Ling, C. and Cherry, N. 2011: Evaluation of a pilot cooperative medical scheme in rural China: impact on gender patterns of health care utilization and prescription practices. BMC Public Health 11,50 .

Liang, X., Guo, H., Jin, C., Peng, X. and Zhang, X. 2012: The effect of new cooperative medical scheme on health outcomes and alleviating catastrophic health expenditure in China: a systematic review. PLoS One 7, e40850.

Liu, H., Gao, S. and Rizzo, J.A. 2011: The expansion of public health insurance and the demand for private health insurance in rural China. China Economic Review $22,28-41$.

Liu, J. 2008: Review on the sprout and its evolution of rural cooperative medical service in Republic of China. Journal of Zhejiang Social Science (in Chinese) 24, 74-80.

McLean, G. and Sutton, M. 2008: What impact did the creation of Local Health Care Co-operatives have on indicators of practice resources and activity? BMC Health Service Research 8, 104.

Nayar, K.R. and Razum, O. 2003: Health co-operatives: review of international experiences. Croatian Medical Journal 44, $568-75$.

Nicola, R.M. 2005: Turning Point's National Excellence Collaboratives: assessing a new model for policy and system capacity development. Journal of Public Health Management and Practice 11, 101-8.

Ralston, J.D., Martin, D.P., Anderson, M.L., Fishman, P.A., Conrad, D.A., Larson, E.B. and Grembowski, D. 2009: Group health cooperative's transformation toward patient-centered access. Medical Care Research and Review 66, 703-24.

Scutchfield, F.D. 2009: The cooperative medical extension program: translation of medical best practices to practicing primary care providers. American Journal of Preventive Medicine 37, 374-76.

Shi, L. 1993: Health care in China: a rural-urban comparison after the socioeconomic reforms. Bulletin of the World Health Organization 71, 723-36.

Sidel, R. and Sidel, V. 1982. The health of China. Boston, MA: Beacon Press.

Sidel, V.W. 1972a: Some observations on the health services in the People's Republic of China. International Journal of Health Services 2, 385-95.

Sidel, V.W. 1972b: The barefoot doctors of the People's Republic of China. The New England Journal of Medicine 286, 1292-300.

Stewart, M.K., Redford, R., Poe, K., Veach, D., Hines, R. and Beachler, M. 2003: The Arkansas river valley rural health cooperative: building a three-pronged approach to 
improved health and health care. The Journal of Rural Health 19 (Suppl), 384-90.

Wang, H., Gu, D. and Dupre, M.E. 2008: Factors associated with enrollment, satisfaction, and sustainability of the new cooperative medical scheme program in six study areas in rural Beijing. Health Policy 85, 32-44.

Wang, H., Gusmano, M.K. and Cao, Q. 2011: An evaluation of the policy on community health organizations in China: will the priority of new healthcare reform in China be a success? Health Policy 99, 37-43.

Wang, S.G. 2008: Learning and adapting: the case of rural healthcare financing in China. Social Science China (in Chinese) 29, 111-33.

White, S.D. 1998: From 'barefoot doctor' to 'village doctor' in Tiger Springs Village: a case study of rural health care transformations in socialist China. Human Organization 57, 480-90.

Xu, W. and Tan, K.C. 2002: Impact of reform and economic restructuring on rural systems in China: a case study of Yuhang, Zhejiang. Journal of Rural Studies 18, 65-81.
Yan, Y.L. 2007: Mao Zedong's views about cooperative medical scheme. Journal of Mao Zedong Thought Study (in Chinese) 24, 36-38.

Yang, Q. 2011: Analysis and recommendations of financing models of new cooperative medical scheme in rural China. Times Finance (in Chinese) 2, 126.

Yang, W. 2013: China's new cooperative medical scheme and equity in access to health care: evidence from a longitudinal household survey. International Journal for Equity in Health 12, 20.

Yip, W. and Hsiao, W. 2009: China's health care reform: a tentative assessment. China Economic Review 20, 613-19.

Zhang, L., Cheng, X., Tolhurst, R., Tang, S. and Liu, X. 2010: How effectively can the new cooperative medical reduce catastrophic health expenditure for the poor non-poor in rural China? Tropical Medicine and International Health 15, 468-75.

Zhu, N.S., Ling, Z.H., Shen, J., Lane, J.M. and Hu, S.L. 1989: Factors associated with the decline of the Cooperative Medical System and barefoot doctors in rural China. Bulletin of the World Health Organization 67, 431-41. 